\title{
A MEMORIA HISTÓRICA NO ESTADO ESPAÑOL: ENTRE O DEREITO DE GRAZA E O DEREITO POSITIVO, A PROPÓSITO DUNHA SENTENZA DO TRIBUNAL SUPREMO DO 13 DE MARZO DE 2017
}

\author{
ERNESTO VÁZQUEZ-REY FARTO \\ Investigador predoutoral na Área de Dereito Administrativo \\ Universidade da Coruña
}

\begin{abstract}
Resumo: O presente comentario versa sobre unha sentenza do Tribunal Supremo, ditada o 13 de marzo de 2017, na que se analizan varios pedimentos sobre a Lei $52 / 2007$, do 26 de decembro, pola que se recoñecen e amplían dereitos e se establecen medidas a favor de quen padeceron persecución ou violencia durante a guerra civil e a ditadura, comunmente denominada Lei da Memoria Histórica, con base na Lei Orgánica 4/2001, do 12 de novembro, reguladora do dereito de petición, tratando de reivindicar a aplicación da Lei da Memoria Histórica como dereito positivo e non como dereito graciábel no Estado español.
\end{abstract}

Palabras chave: Memoria histórica; dereito de petición; franquismo; Guerra civil española; exhumacións.

Resumen: El presente comentario versa sobre una sentencia del Tribunal Supremo, dictada el 13 de marzo de 2017, en la que se analizan varias peticiones sobre la Ley $52 / 2007$, de 26 de diciembre, por la que se reconocen y amplían derechos y se establecen medidas a favor de quienes padecieron persecución o violencia durante la guerra civil y la dictadura, comunmente denominada Lei de la Memoria Histórica, con base en la Ley Orgánica 4/2001, de 12 de noviembre, reguladora del derecho de petición, tratando de reivindicar la aplicación de la Ley de Memoria Histórica como derecho positivo y no como derecho graciable en el Estado español.

Palabras clave: Memoria histórica; derecho de petición; franquismo; Guerra civil española; exhumaciones. 
1. Na sentenza da Sala do Contencioso-Administrativo, Sección Cuarta, do Tribunal Supremo que se vai tratar, e que leva por data o 13 de marzo de 2017 no número de procedemento 4266/2016 ${ }^{1}$, procede analizar o tipo de amparo legal que asiste ás vítimas do franquismo e ás súas familias, ubicado entre o Dereito graciábel e o Dereito positivo, singularizados na Lei Orgánica 4/2001, do 12 de novembro, reguladora do dereito de petición $^{2}$, e na Lei 52/2007, do 26 de decembro, pola que se recoñecen e amplían dereitos e se establecen medidas a favor de quen padeceron persecución ou violencia durante a guerra civil e a ditadura ${ }^{3}$. Para comprender mellor a problemática que se formula é preciso realizar unha síntese sucinta do marco sobre o que se vai tomar a decisión que -en adianto- será negativa á toma en consideración de varias peticións relativas ao disposto na Lei 52/2007, comunmente -e en diante- denominada Lei da Memoria Histórica. Os elementos a ter en conta son: (a) os avogados Baltasar Garzón Real, Manuel Ollé Sesé e Eduardo Ranz Alonso presentan o 19 de novembro de 2015 unha petición ao Ministerio da Presidencia na que formulan sete medidas concretas a adoptar polo Consello de Ministros en atención á Lei da Memoria Histórica; (b) o Ministerio da Presidencia acusa recibo da recepción da petición referida o 27 de novembro de 2015, solicitando informe ao Ministerio de Xustiza e a Patrimonio Nacional; (c) os tres peticionarios presentan recurso contencioso-administrativo, o 1 de marzo de 2016, polo procedemento especial de protección xurisdicional dos dereitos fundamentais da persoa, en defensa do dereito de petición prescrito no artigo 29.1 da Constitución española (en diante, CE) ${ }^{4}$, ao terse sobrepasado o límite de tres meses por parte do Consello de Ministros para contestar e notificar a contestación aos peticionarios $^{5}$; (d) a Sala do Contencioso-Administrativo do Tribunal Supremo recibe o expediente administrativo, que se entrega á parte recorrente, concedéndolle trámite para formular o correspondente escrito de demanda, que se presenta o 29 de xullo de 2016, no que se solicita a declaración de vulneración do dereito fundamental de petición e a asunción por parte do Consello de Ministros de sete medidas concretas en relación coa Lei da Memoria Histórica; (e) trasladada a demanda e o expediente administrativo á parte recorrida, o Ministerio Fiscal, por escrito do 14 de setembro de 2016, interesa a

\footnotetext{
1 Pódese consultar o texto completo na seguinte ligazón: http://www.poderjudicial.es/search/contenidos.action?action=contentpdf \&databasematch=TS\&reference= 7965452\&links $=\& o p t i m i z e=20170321 \&$ publicinterface $=$ true [Consultado o 09/06/2017]

2 Publicada a versión en galego o 1 de decembro de 2001, no suplemento número 15 do BOE, número 272, do 13 de novembro de 2001: https://www.boe.es/boe_gallego/dias/2001/12/01/pdfs/A0131801320.pdf [Consultado o 09/06/2017]

${ }^{3}$ Publicada a versión en galego o 28 de decembro de 2007, no suplemento número 34 do BOE, número 310, do 27 de decembro de 2007: http://boe.es/boe_gallego/dias/2007/12/28/pdfs/A04370-04376.pdf [Consultado o 09/06/2017]

4 "1. Todos los españoles tendrán el derecho de petición individual y colectiva, por escrito, en la forma y con los efectos que determine la ley."

${ }^{5}$ Obriga recollida no artigo 11.1 da Lei Orgánica 4/2001, do 12 de novembro, reguladora do dereito de petición.
} 
estimación da demanda, declarando o dereito dos recorrentes a obteren unha resposta á súa petición e condenando ao Consello de Ministros a formular a contestación na forma que marca o referido artigo 11.3 da Lei Orgánica 4/2001, de peticións; (f) o avogado do Estado presenta, o 16 de setembro de 2016, escrito de contestación á demanda no que suplica que o Tribunal "acuerde la inadmisión de la demanda o, en su caso, su desestimación, con imposición de las costas"; (g) a Sala do Contencioso-Administrativo do Tribunal Supremo recibe, o 16 de setembro de 2016, oficio do Ministerio da Presidencia remitindo expediente administrativo complementario no que se inclúe copia do acordo do Consello de Ministros -aprobado nesa mesma data- polo que se contesta ao escrito de petición dos tres recorrentes; (h) o 20 de setembro de 2016 dase traslado ás partes, mediante dilixencia de ordenación, da documentación complementaria referida para que formulen alegacións. Neste sentido, a parte actora insiste no incumprimento do prazo máximo de contestación de tres meses no que incorreu o Consello de Ministros, vulnerando o dereito de petición recollido na $\mathrm{CE}$, solicitando que se obvie o expediente administrativo complementario remitido polo Ministerio da Presidencia. A Avogacía do Estado suplica que se dite sentenza nos termos establecidos na contestación á demanda e o Ministerio Fiscal interesa que o Tribunal desestime a mesma por carencia sobrevida do obxecto ou, subsidiariamente, por non existir vulneración do dereito fundamental de petición da parte actora; (i) a Sala do Contencioso-Administrativo do Tribunal Supremo, por auto do 28 de setembro de 2016, acorda non recibir a proba o recurso e ao non terse presentado conclusións escritas ou vista, declaráronse concluídas as actuacións; (1) o 28 de febreiro de 2017 tivo lugar a votación e fallo do recurso contencioso-administrativo de referencia.

2. A sentenza comeza precisando o límite constitucional do dereito fundamental de petición, tendo en conta o alcance das pretensións invocadas pola parte actora. Ademáis, examina dous ámbitos de pretensións, separábeis polo seu distinto fundamento xurídico; a saber, a declaración da vulneración do dereito de petición, dada a omisión de contestación no prazo legalmente establecido, e a confirmación de se a contestación dada polo Consello de Ministros á petición da parte actora cumpre os requirimentos da Lei de Peticións.

En canto á circunscrición constitucional do dereito de petición e a súa protección xurisdicional, o Tribunal Supremo lembra que a propia Sala do ContenciosoAdministrativo declarou reiteradamente que o dereito de petición, recollido no artigo 29.1 da CE e desenvolvido pola Lei de Peticións, en ningún caso leva aparellada a obriga, por parte da Administración Pública perante a que se exerce, de acoller o que se pide $^{6}$. No relativo ás pretensións invocadas polos actores, o Tribunal aborda en primeiro

\footnotetext{
${ }^{6}$ A mesma Sala na sentenza do 14 de decembro de 2016, sobre o recurso de casación núm. 2265/2015, declarou que o dereito de petición "[...] [s]e distingue por servir de cauce para aquellas pretensiones que no tienen estatuto de derecho ni de interés legítimo. Y se ha caracterizado, por un lado, por impedir que quien lo ejerce sufra como consecuencia de ello sanciones o decisiones que le perjudiquen y, por el otro, porque las únicas facultades que comporta son las de exigir el acuse de recibo y la comunicación de la decisión adoptada al respecto o bien la remisión a quien sea competente para tomarla, quien habrá de dar esa respuesta. En ningún caso conlleva el derecho de petición la obligación por parte del poder público frente al que se ejerce de acogerla materialmente. La Ley Orgánica 4/2001 se ajusta al contenido que históricamente se ha reconocido a este derecho. Así, su artículo 1, que lo extiende a toda persona natural o jurídica prescindiendo de su nacionalidad, mientras el artículo 29 de la Constitución solamente lo refiere a los españoles, veda que el peticionario pueda verse perjudicado por el ejercicio de este derecho salvo que comporte delito o falta y, luego, los artículos 3, segundo párrafo, y 8, segundo párrafo, dejan claro que no pueden canalizarse a través del derecho de petición aquellas solicitudes o pretensiones para las que exista un procedimiento específico. $Y$ es que, como dice la exposición de motivos de ese texto legal del derecho fundamental que regula: "su carácter supletorio respecto a los
} 
termo a pretensión de que se declare a vulneración do dereito de petición, pola omisión da obriga de contestar no prazo de tres meses, prescrito na Lei de Peticións. Neste sentido, a sentenza obxecto de análise indica que os actores rexeitan toda virtualidade xurídica á contestación da súa petición, segundo o acordo do Consello de Ministros do 16 de setembro de 2016, querendo manter o debate sobre a eventual vulneración do dereito de petición no plano estritamente formal. Di o Tribunal que a falta de contestación no prazo establecido tan só permitiría a estimación do recurso, obrigando á Administración a contestar, segundo o esixido no artigo 12.b) da antedita Lei de Peticións. Non obstante, o Consello de Ministros deu contestación á petición e notificóulla á parte actora, aínda fóra de prazo, polo que a Sala non pode asumir a pretensión, xa que a notificación da contestación á petición inicial integra o núcleo do dereito fundamental que supoñen vulnerado ${ }^{7}$, polo que se considera producida a perda sobrevida do obxecto respecto do primeiro suplico da demanda ${ }^{8}$, tal e como sostivo o Ministerio Fiscal no seu escrito de alegacións. En canto á segunda pretensión, relativa a se a contestación dada polo acordo do Consello de Ministros cumpre os requisitos do artigo 11.3 da Lei de Peticións, o Tribunal decide non atender a solicitude do avogado do Estado de que sexa inadmitido o recurso, xa que nin ese é o sentido da contestación do Consello de Ministros, nin o eventual exceso das pretensións dos actores -no exercicio do seu dereito de petición- permite un pronunciamento de inadmisión do recurso contencioso administrativo. Constata a Sala que a contestación do Consello de Ministros á petición dos actores é axeitada e satisfai íntegramente o dereito fundamental de petición que os asiste.

A contestación -en sentido desfavorábel- do Consello de Ministros á petición dos avogados Baltasar Garzón, Manuel Ollé e Eduardo Ranz, que é a peza determinante no fallo do Tribunal Supremo, analiza as sete medidas solicitadas, que se expresan sucintamente: $1^{\circ}$ ) A anulación do Decreto do 1 de abril de 1940 e do Decreto-Lei do 23

procedimientos formales específicos de carácter parlamentario, judicial o administrativo obliga a delimitar su ámbito a lo estrictamente discrecional o graciable, a todo aquello que no deba ser objeto de un procedimiento especialmente regulado". Por otro lado, el artículo 11, precisa cómo han de tramitarse y resolverse las peticiones admitidas. De sus prescripciones interesa destacar que el órgano receptor de las mismas, de ser competente, habrá de contestarlas en tres meses desde su presentación y que está obligado, en los supuestos en que no las estime fundadas a recoger, al menos, los términos en los que la petición ha sido tomada en consideración por parte de la autoridad u órgano competente y a incorporar las razones y motivos por los que se acuerda no acceder a ella (apartado 3). [...] En fin, el artículo 12 de la Ley Orgánica 4/2001 fija, en coherencia con la naturaleza del derecho de petición, el alcance de su protección jurisdiccional. Así, mediante ella podrá combatir: a) la declaración de inadmisibilidad de la petición; b) la omisión de la obligación de contestarla en el plazo establecido; y c) la ausencia en la contestación de los requisitos mínimos establecidos en el artículo 11". También la doctrina del Tribunal Constitucional ha destacado en su sentencia de 20 de junio de 2011 (108/2011) reiterando anteriores resoluciones que "en nuestra STC 242/1993, de 14 de julio, F. 2, ya afirmamos que el derecho de petición incluye la exigencia de admisión del escrito que incorpora la petición, de su tramitación conforme al curso debido o de su reenvío al órgano competente si no lo fuera el receptor, tomando en consideración el contenido del escrito, lo que no significa, sin embargo, que ello "incluya el derecho a obtener respuesta favorable a lo solicitado" ".

7 "[...] Tal y como declaramos en nuestra sentencia de 20 de marzo de 2007 (recurso contencioso administrativo 141/2007) [...] el hecho de que se hubiera rebasado el plazo máximo para la notificación de la contestación no priva a la misma de su virtualidad en orden a satisfacer el derecho de petición, limitando la declaración dirigida al restablecimiento del derecho de petición a la notificación de la contestación. [...]."

8 "[...] La desaparición sobrevenida del objeto es un modo de terminación del proceso reiteradamente admitido no sólo por la Jurisprudencia de esta Sala del Tribunal Supremo (por todas, sentencia de 20 de octubre de 2011), sinó también por la doctrina del Tribunal Constitucional, como precisa su sentencia núm. 95/2009, de 25 de abril [...]." 
de agosto de 1957, que non se leva a cabo porque segundo a Disposición Derrogatoria Terceira da CE quedan sen efecto cantas disposicións se opoñan ás súas regras e principios $\left.{ }^{9} ; 2^{\circ}\right)$ A aprobación dunha disposición de carácter xeral que estableza un novo marco xurídico polo cal teña que rexerse o Val dos Caídos, e a institución que o dirixe, os seus bens e cantas outras relacións e situacións xurídicas poidan verse afectadas, que non se toma en consideración, xa que a recomendación $22^{\mathrm{a}}$ do Informe da Comisión de Expertos $^{10}$ indica que o esforzo económico que supón "exige previamente una pacificación social y política del Valle de los Caídos que legitime el mantenimiento y cuidado de este conjunto monumental y haga del Valle un lugar de encuentro de todos los españoles, fueren cuales fueren sus ideologías"; $3^{\circ}$ ) A nova normativa debe incluir a transformación do Val dos Caídos nun espazo de memoria onde as vítimas da guerra civil e a ditadura e os seus familiares, así como a sociedade no seu conxunto, poidan exercitar o seu dereito á verdade e á reparación, amparándose no Informe do Relator Especial sobre a promoción da verdade, a xustiza, a reparación e as garantías de non repetición, do 22 de xullo de 2014, suxírense vías alternativas á exhumación cando non sexa materialmente posíbel ${ }^{11} ; 4^{\circ}$ ) $O$ traslado dos restos de Francisco Franco Bahamonde e de José Antonio Primo de Rivera y Sáenz de Heredia ao lugar que designen as súas respectivas familias, non se entende viábel ao abeiro das recomendacións da Comisión de Expertos que destaca "las dificultades para revertir la situación creada por los enterramientos en la Basílica" toda vez que "cualquier actuación del Gobierno en el interior de la Basílica exige una actitud de colaboración por parte de la Iglesia que es a quién se ha confiado la custodia de sus restos [...]"; 5) A dotación económica suficiente a cargo do Estado, para a exhumación e identificación dos restos das vítimas inhumadas no lugar, previa solicitude ao efecto, na que a Comisión de Expertos advirte que "el deterioro de las criptas y los columbarios, unido al volumen de restos enterrados, hace prácticamente imposible como norma general, la identificación individualizada"; $6^{\circ}$ ) Convocatoria dun acto público na sede parlamentar para que a autoridade competente do Estado pida perdón ás vítimas do franquismo e aos seus familiares, que non se contempla, pola necesidade dun amplo consenso social e político; e $7^{\circ}$ ) Adoptar as medidas oportunas para que a Comisión á que se refire o Real Decreto 663/1984, do 25 de xaneiro, cumpra o seu cometido no marco da actual regulación vixente, introducida pola Lei da Memoria Histórica, que tampouco se explicitan na resolución do Consello de Ministros.

3. A sentenza aquí analizada versa sobre un tema tan interesante como polémico no que ten a ver coa aplicación dos principios da Memoria Histórica no Estado español, se ben o cauce procesual empregado polos peticionarios é o do dereito de petición, que implica apelar a unha facultade discrecional da Administración, e non o da aplicación directa da Lei 52/2007, do 26 de decembro, pola que se recoñecen e amplían dereitos e se

\footnotetext{
${ }^{9}$ O Tribunal Constitucional nas STC 77/1982, do 20 de decembro, e STC 80/1983, do 10 de outubro, indicou que se unha lei reguladora dun dereito fundamental é preconstitucional e infrinxe a CE "debe considerarse inaplicable en lo que vulnere dicha norma constitucional por haber quedado derogada (...), y todo ello sin necesidad de que el Legislador, la Administración o los Tribunales, según los casos, hagan una declaración en tal sentido".

${ }^{10}$ Comisión de Expertos para o futuro do Val dos Caídos, creada por acordo do Consello de Ministros do 27 de maio de 2011, co cometido de elaborar un Informe sobre as posíbeis actuacións a desenvolver no conxunto monumental, no marco do previsto na Disposición Adicional Sexta da Lei da Memoria Histórica.

${ }^{11} \mathrm{Na}$ súa recomendación 29: "Atender los reclamos de quienes exigen recuperar los restos de sus familiares inhumados ahí sin su consentimiento. Cuando no sea materialmente posible, diseñar e implementar, con la participación de los familiares, medidas adecuadas de reparación, incluyendo medidas simbólicas o de dignificación".
} 
establecen medidas a favor de quen padeceron persecución ou violencia durante a guerra civil e a ditadura, que sería o máis axeitado, na opinión de quen suscribe. Neste sentido, a Lei Orgánica 4/2001, do 12 de novembro, reguladora do dereito de petición, recolle no seu artigo 11.1 a obriga de notificar a contestación á petición no prazo máximo de tres meses, prazo dende o cal cabe a protección xurisdicional do dereito fundamental de petición. Non obstante, malia que a doutrina do Tribunal Supremo sinala que a notificación da contestación dada a unha petición supón o núcleo do dereito fundamental, outorga á contestación extemporánea a mesma consideración que á dada no prazo prescrito pola Lei, o cal acaba outorgando unha sorte de papel preponderante ao Poder Público que acaba por non ter ningunha consecuencia procesual no flagrante incumprimento dunha Lei Orgánica, reguladora dun dereito constitucional fundamental, como é o dereito de petición. Con todo, a fundamentación do acordo do Consello de Ministros do 16 de setembro de 2016, polo que se contesta á petición formulada por Baltasar Garzón, Manuel Ollé e Eduardo Ranz, obvia dous preceptos vixentes na Lei da Memoria Histórica que se están a conculcar e que formaban parte da petición remitida polos actores, como é o caso do artigo 16, relativo ao Val dos Caídos, e a Disposición Adicional $6^{\mathrm{a}}$, que limita a actuación da fundación xestora do propio recinto. Así, resulta altamente significativo que actualmente se sigan a manter en boas condicións de limpeza e acondicionamento os sepulcros do ditador, Francisco Franco, e do fundador da Falange Española, José Antonio Primo de Rivera, soterrados no interior da Basílica do Val dos Caídos, sen que isto entre en contradición co establecido na Lei da Memoria Histórica, ao ser considerado -a xuízo de quen suscribe- un acto de exaltación da guerra civil e do franquismo, dada a inexistente atención para coas demáis criptas e columbarios nos que están inhumados innumerábeis restos de vítimas; todo o cal constitúe unha obriga legal da Fundación da Santa Cruz do Val dos Caídos, tal e como prescribe a inusitadamente aplicada Lei da Memoria Histórica. 